\section{Freedoms and rights}

Stephen Hancocks OBE

Editor-in-chief

I have sat through many meetings and read a lot of articles on the subject of editorial freedom but have very often been surprised at what I have considered to be the naivety of the majority of the views which require or better yet 'demand' such freedom as a right.

Every publication has an owner. It may an individual or it may be more than one person, an association or society for example, or it may be a collective or an alliance but someone, somewhere owns the title. I am therefore not at all sure why there should be any doubt that any sense of editorial policy should be anything other than reflective of the owner's wishes and interests. As I have written here recently, we are all potentially journalists and editors now thanks to the internet and we are hardly likely as individuals to write, speak or publish thoughts or opinions which we do not hold.

I raise this because I think that it is easy to get confused about freedoms and rights. These are privileges and responsibilities accorded by others to us in the context of a club, society, state or country. So we have no absolute rights, they have to be negotiated, agreed and earned within a framework.

\section{PRACTISE REGAINED FOR DENTISTS LIVING WITH HIV}

Until the recent, and very welcome, announcement by the Department of Health that healthcare workers with bloodborne viruses, and in the case of our profession in particular dentists with HIV, can now practise providing they can prove that they are taking antiretroviral drugs and are being monitored, these colleagues did not have either the right or the freedom to continue to apply their professional skills.

The Department's decision is in line with the government's own advisory committee's recommendations nearly two years ago and while it is very pleasing that the announcement has now been made, it is also distressing that it has taken so long. In the light of this, various other questions and considerations will doubtless arise. Are colleagues affected by this change of policy entitled to compensation for the livelihood lost as a result of the former restrictions? For those who have been out of practice for, presumably in some cases many years, will appropriate re-training or updating be assisted and paid for by the state? How will the GDC's requirements be applied? These matters will now need to be discussed and further negotiated in the coming weeks and months but at least the decision is made.

This Journal, thanks to its editorial freedom, has campaigned for a change in the regulations since 2006. We pub- lished an editorial and an 'Opinion' piece by David Croser, a stalwart campaigner in this matter, and a subsequent opinion piece by a general dental practitioner graphically explaining how his HIV status had robbed him of his ability to practise his chosen profession any longer. ${ }^{1-3}$ The galling aspect of the situation was that all evidence, then and now, pointed and points to there being no appreciable threat to public (patient) safety as a result of practitioners so affected treating them, even with exposure prone procedures.

What I think is important about this common sense change of regulations is that it has come about due to a fight, if that is the correct word, or at least a challenge for a freedom and, in a sense, a right. With the advent of HIV, and of AIDS, there was a lack of clarity about its infectivity, its epidemiology, routes of transmission and so forth. That initial confusion understandably spread anxiety and fear at many levels of society in the UK and worldwide causing what may now seem like an over-reaction but what at the time was considered to be prudent precautions. With knowledge comes clarity and power, and the time to apply it has been overdue.

The BDA must also therefore be credited with its support for this change, which has been unequivocal from many individual members, authors of letters to the editor and from the former Representative Body and its successor, the Principle Executive Committee. The Association has also very effectively demonstrated editorial freedom in (in my opinion) the very best and positive way and should be congratulated for doing so. What it has done has been to use the democratic means available to link with others and put a logical, evidence-based argument to the government and has, at last, seen its petition succeed. In the current climate of challenges to professional autonomy it also has a strange, perhaps slightly ironic but reassuring, sense of balanced justice about it. It is a very good development and should be recognised and celebrated as such. It is a hard earned right and it provides a freedom the type of which we should be proud of both as a profession and a society. Together, as the term has it, we are stronger. With thanks.

1. Hancocks S. Losing your livelihood just twenty minutes from now. Br Dent J 2006; 201: 485.

2. Croser D. Written off. Br Dent J 2006; 201: 497-499.

3. Anon. 'This was something that happened to someone else' - an HIV positive dentist explains. Br Dent J 2006; 201: 697-698.

DOI: 10.1038/sj.bdj.2013.793 